\title{
Cranioplasty with patient-specific implants in repeatedly reconstructed cases
}

Citation for published version (APA):

Koper, D., ter Laak-Poort, M., Lethaus, B., Yamauchi, K., Moroni, L., Habibovic, P., \& Kessler, P. (2019). Cranioplasty with patient-specific implants in repeatedly reconstructed cases. Journal of CranioMaxillofacial Surgery, 47(5), 709-714. https://doi.org/10.1016/j.jcms.2019.01.034

Document status and date:

Published: 01/05/2019

DOI:

10.1016/j.jcms.2019.01.034

Document Version:

Publisher's PDF, also known as Version of record

Document license:

Taverne

Please check the document version of this publication:

- A submitted manuscript is the version of the article upon submission and before peer-review. There can be important differences between the submitted version and the official published version of record.

People interested in the research are advised to contact the author for the final version of the publication, or visit the DOI to the publisher's website.

- The final author version and the galley proof are versions of the publication after peer review.

- The final published version features the final layout of the paper including the volume, issue and page numbers.

Link to publication

\footnotetext{
General rights rights.

- You may freely distribute the URL identifying the publication in the public portal. please follow below link for the End User Agreement:

www.umlib.nl/taverne-license

Take down policy

If you believe that this document breaches copyright please contact us at:

repository@maastrichtuniversity.nl

providing details and we will investigate your claim.
}

Copyright and moral rights for the publications made accessible in the public portal are retained by the authors and/or other copyright owners and it is a condition of accessing publications that users recognise and abide by the legal requirements associated with these

- Users may download and print one copy of any publication from the public portal for the purpose of private study or research.

- You may not further distribute the material or use it for any profit-making activity or commercial gain

If the publication is distributed under the terms of Article $25 \mathrm{fa}$ of the Dutch Copyright Act, indicated by the "Taverne" license above, 


\title{
Cranioplasty with patient-specific implants in repeatedly reconstructed cases
}

\author{
David Koper a, e, f, *, Mariel ter Laak-Poort ${ }^{\text {b }}$, Bernd Lethaus ${ }^{\text {c }}$, Kensuke Yamauchi ${ }^{\text {d }}$, \\ Lorenzo Moroni ${ }^{\mathrm{e}}$, Pamela Habibovic ${ }^{\mathrm{f}}$, Peter Kessler ${ }^{\mathrm{a}}$ \\ a Department of Cranio-Maxillofacial Surgery, Maastricht University Medical Center, PO Box 5800, 6202 AZ, Maastricht, the Netherlands \\ b Department of Neurosurgery, Maastricht University Medical Center, PO Box 5800, 6202 AZ, Maastricht, the Netherlands \\ ' Department of Cranio-Maxillofacial Surgery, RWTH Aachen University, Pauwelstraße 30, 52074, Aachen, Germany \\ ${ }^{\mathrm{d}}$ Division of Oral and Maxillofacial Surgery, Department of Oral Medicine and Surgery, Tohoku University Graduate School of Dentistry, 4-1 Seiryo-machi, \\ Aoba-ku, Sendai, Miyagi, 980-8575, Japan \\ e Department of Complex Tissue Regeneration, MERLN Institute for Technology Inspired Regenerative Medicine, Maastricht University, PO Box 616, 6200 \\ MD, Maastricht, the Netherlands \\ ${ }^{\mathrm{f}}$ Department of Instructive Biomaterials Engineering, MERLN Institute for Technology Inspired Regenerative Medicine, Maastricht University, PO Box 616, \\ 6200 MD, Maastricht, the Netherlands
}

\section{A R T I C L E I N F O}

\section{Article history:}

Paper received 17 July 2018

Accepted 25 January 2019

Available online 14 February 2019

\section{Keywords:}

Cranioplasty

Polyetheretherketone

Titanium

Patient-specific implant

CAD-CAM

\begin{abstract}
A B S T R A C T
Objective: Cranioplasty is indicated to restore form and function of bone defects of the neurocranium. Autografts are the gold standard, alloplastic materials are used when autologous bone is unavailable or unsuitable, and increasing evidence supports the use of patient-specific implants (PSIs) for reconstruction. We reviewed our own patient data to assess pre- and intraoperative aspects, complications and costs in patients that were treated with PSIs from titanium or polyetheretherketone (PEEK) for skull bone reconstruction.

Methods: We retrospectively evaluated all patients receiving a PSI as at least a secondary reconstruction between 2004 and 2016 at Maastricht University Medical Center. These cases were analyzed for demographics, perioperative surgical and medical aspects, as well as costs.

Results: In total 30 patients received PSIs, of which 20 were included in this study. Duration of PSI placement was not statistically different between group I, where previously placed reconstruction material was still in situ, and group II, where no remaining previously placed reconstruction material was present (group I: $104 \pm 27$ mins, group II: $86 \pm 36$ mins; $\mathrm{p}=0.27$ ). Postoperatively, 2 patients experienced complications (10\%). Costs of obtaining the PSIs were not significantly different between group I and group II (group I: mean EUR $7536 \pm 2759$, group II: mean EUR $8351 \pm 2087, \mathrm{p}=0.51$ ).

Conclusion: Treatment of skull bone defects in repeated reconstruction requires an optimal preoperative planning and intraoperative procedure. In this retrospective study comparing repeatedly reconstructed cases with and without remaining previously placed reconstruction material present at the surgical site, we could not find significant differences in the duration of the surgical procedure nor costs of obtaining the PSIs. The protocol followed at MUMC for preoperative planning, manufacturing, and surgery, represents the current state-of-the-art treatment.
\end{abstract}

๑) 2019 European Association for Cranio-Maxillo-Facial Surgery. Published by Elsevier Ltd. All rights reserved.

\footnotetext{
* Corresponding author. Department of Cranio-Maxillofacial Surgery, Maastricht University Medical Center, PO Box 5800, 6202 AZ, Maastricht, the Netherlands. Tel: +31 43387 2010. Fax: +31433872020.

E-mail address: d.koper@mumc.nl (D. Koper).
}

\section{Introduction}

Cranioplasty, the repair of neurocranial defects, remains a challenging procedure in reconstructive craniofacial surgery. Defects of the neurocranium can occur for many reasons, e.g. after decompression surgery for stroke, craniectomy for intracerebral infections or trauma, oncological resections, or craniectomy for epilepsy or aneurysm surgery. The reconstruction of neurocranial defects is important to restore both form (symmetry) and function 
(protection and function of the brain, improvement of quality of life), and always involves surgery (Zegers et al., 2017). Neurocranial defects can be of considerable size (i.e. over $100 \mathrm{~cm}^{2}$ ) and are disfiguring. The size, anatomical location and extent of the defect, and involvement of the orbital rim, e.g., are directly related to the possibilities but also to the difficulties of this delicate surgery (Poukens et al., 2008).

The use of autologous bone is still regarded as the gold standard in reconstruction of any kind of bone defect. The autologous bone graft, harvested during a craniectomy procedure, e.g., can be replaced, or new bone can be harvested from a donor site in the same patient, if the original material is absent or unsuitable for other reasons. The latter is time-consuming, adds donor site morbidity, and is impossible in cases in which no donor site is suitable to provide an adequate amount of bone to restore the defect (Lethaus et al., 2011). Additionally, there is a risk of resorption of the grafted bone. Using autologous bone for cranioplasty is associated with a failure rate of up to 30\% (Kimchi et al., 2016; Hng et al., 2015). Alternatively, alloplastic materials can be used for reconstruction. Alloplastic materials can either be used in a standardized off-the-shelf form, subsequently made to fit during surgery, or preoperatively customized to fit the patient's defect on a truly individualized basis. Frequently used alloplastic materials include metals such as titanium (Ti), acrylics such as polymethylmethacrylate (PMMA), ceramics (hydroxyapatite [HA]), or polymers such as polyetheretherketone (PEEK) (Zanotti et al., 2016). Over the last decade, patient-specific implants (PSIs), designed and manufactured using computer-aided design/computer-aided manufacturing (CAD-CAM) technology, became available for primary, secondary and subsequent cranioplasty. Based on a CT scan of the patient, an implant is virtually designed using CAD software, and manufactured through either subtraction methods (high-speed milling) or additive manufacturing techniques (Lethaus et al., 2011, 2014; Park et al., 2016).

It is important to notice that the neurological status or recovery of a patient is leading in the planning of reconstructive procedures related to the neurocranium. The surgical difficulties result from various factors. In most cases, the time between craniectomy and reconstruction is difficult to estimate, as the recovery and rehabilitation of a patient can take months or years. However, if autologous bone is stored for a long time, the chances of reintegration and revitalization of these specimen diminish, leading to resorption instead of remodeling (Brommeland et al., 2015). It is not unusual that still today patients with multiple attempts of neurocranial reconstructions present to specialized units such ours at Maastricht University Medical Center (MUMC).

This study refers exclusively to patients with repeatedly reconstructed neurocranial defects. We present data related to planning, duration of surgical procedure, complication rate, and costs. All patients received PSIs made from titanium or PEEK.

\section{Materials and methods}

\subsection{Selection of patients and data acquisition}

The medical records of all patients who underwent cranioplasty with a PSI at the Department of Cranio-Maxillofacial Surgery of MUMC between 2004 and 2016 were reviewed. Patients that received a PSI as at least a secondary reconstruction were included in this study. Patients without previous reconstruction and cases with insufficient data were excluded. Data for both titanium and PEEK reconstructions were pooled for analyses, and no comparison between titanium and PEEK was made.

From the medical records of the included patients, the following information was extracted: sex, age at PSI placement, diagnosis leading to craniectomy, type and timing of previous non-PSI reconstruction(s), diagnosis leading to failure of non-PSI reconstruction(s), defect size classification, presence or absence of previously placed reconstruction material at the time of PSI placement, PSI material and manufacturer, duration of the surgical procedure of PSI placement, postoperative complications, and costs of obtaining the PSIs.

All information was available either through digitalized paper charts or electronic medical records (SAP GmbH, Walldorf, Germany).

\subsection{Defect classification}

The defects were classified according to earlier reports in the literature. This classification includes the size of the defect, orbital involvement and whether the sagittal midline of the skull is crossed. It ranges from class I to VI with increasing difficulty in design and manufacturing of PSIs (Poukens et al., 2008).

\subsection{Variables}

The duration of the surgical procedure of PSI placement was compared between the group of patients who still had remaining cranioplasty material (or remnants thereof) in situ (group I) with the group who did not have remaining cranioplasty material in situ (group II). Other variables were the postoperative complication rate and the costs of obtaining the PSIs.

\subsection{Statistical analysis}

Statistical analysis was performed using SPSS 24 (IBM Corp., Armonk NY, USA). A Kolmogorov-Smirnov test was used to assess all continuous variables for normality, given the small sample sizes. A two-sided independent t-test was used to analyze differences in the operation time, and a one-sided independent t-test was used to analyze the hypothesized decrease in cost of PSIs. Statistical significance was set at $\mathrm{p} \leq 0.05$.

\subsection{Ethical approval}

This study was approved by our local medical ethical committee (METC 17-04-039).

\section{Results}

Between 2004 and 2016, a total of 30 patients underwent cranioplasty with a PSI at MUMC. Of these patients, 20 patients had received an earlier non-PSI reconstruction of the neurocranial defect and were included in this study. Eight patients had not previously undergone reconstruction and were excluded from this study. Two additional patients were excluded because of insufficient data. According to the defect size classification of Poukens et al., 10 patients had a class II, 9 patients a class III, and 1 patient a class IV skull bone defect (Poukens et al., 2008). A flowchart of inclusion and exclusion of cases is presented in Fig. 1.

The diagnoses leading to craniectomy were tumor $(n=7)$, trauma $(n=5)$, epilepsy or aneurysm $(n=3)$, stroke $(n=3)$, and intracranial infection $(n=2)$. Of the 20 patients who had received an earlier nonPSI reconstruction, 10 patients received a cranioplasty during the initial craniectomy procedure. In 7 patients, the autologous bone graft was replaced. Two patients received a PMMA reconstruction, and 1 patient underwent reconstruction with a titanium mesh. A cranioplasty at a later stage was performed in the other 10 patients. Nine patients underwent replacement of the autologous bone graft. One patient underwent reconstruction using autologous rib grafts. A summary of the patient data is presented in Table 1 . 


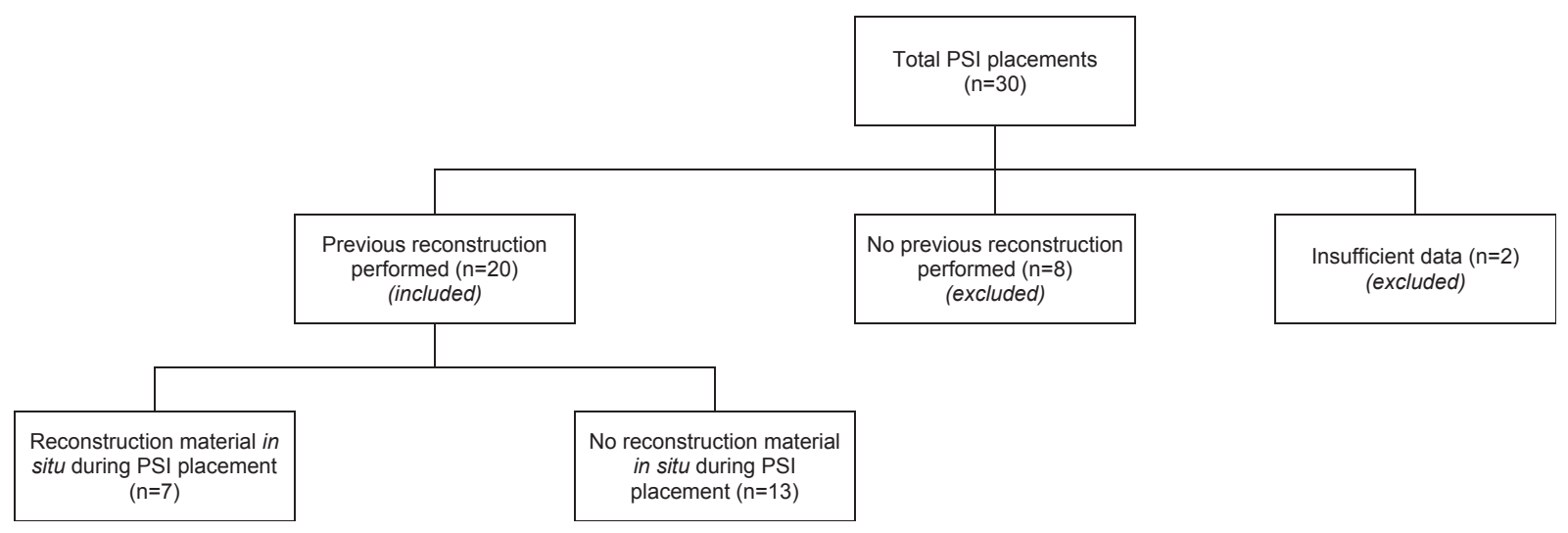

Fig. 1. Flowchart of in- and exclusion of cases.

Table 1

Patient data.

\begin{tabular}{|c|c|}
\hline Patient data, $\mathrm{n}=20$ & \\
\hline \multicolumn{2}{|l|}{ Sex, n (\%) } \\
\hline Male & $15(75)$ \\
\hline Female & $5(25)$ \\
\hline Age at PSI placement, mean (SD) & $42( \pm 17)$ \\
\hline \multicolumn{2}{|l|}{ Diagnosis leading to craniectomy, $\mathrm{n}(\%)$} \\
\hline Tumor & $7(35)$ \\
\hline Trauma & $5(25)$ \\
\hline Epilepsy or aneurysm & $3(15)$ \\
\hline Stroke & $3(15)$ \\
\hline Intracranial infection & $2(10)$ \\
\hline \multicolumn{2}{|l|}{ Defect class, n (\%) } \\
\hline II & $10(50)$ \\
\hline III & $9(45)$ \\
\hline IV & $1(5)$ \\
\hline \multicolumn{2}{|l|}{ Previous reconstruction, $\mathrm{n}(\%)$} \\
\hline Replacement of autologous bone graft & $16(80)$ \\
\hline PMMA & $2(10)$ \\
\hline Titanium mesh & $1(5)$ \\
\hline Autologous bone transplant & $1(5)$ \\
\hline \multicolumn{2}{|l|}{ Indication for PSI reconstruction, $\mathrm{n}(\%)$} \\
\hline Infection bone graft & $11(55)$ \\
\hline Infection of alloplastic material & $2(10)$ \\
\hline Resorption bone graft & $4(20)$ \\
\hline Remaining defect, contour correction & $1(5)$ \\
\hline Mechanical failure of non-PSI material & $1(5)$ \\
\hline Other & $1(5)$ \\
\hline \multicolumn{2}{|l|}{ PSI material, n (\%) } \\
\hline Titanium & $5(25)$ \\
\hline PEEK & $15(75)$ \\
\hline
\end{tabular}

In 13 of 20 patients (65\%), the material previously placed during cranioplasty was removed entirely in a separate procedure before reconstruction with a PSI. The indication for removal was infection in all 13 cases. The duration of the surgical procedure to remove the previously placed cranioplasty material was retrievable in 7 cases, and was a mean of $67 \pm 43$ min (Table 2). In 7 of 20 patients (35\%), the previously placed cranioplasty material or remnants thereof were still present at the time of PSI placement. Indications for reconstruction with a PSI were as follows: bone resorption in 4 patients (Fig. 2), 1 patient had a remaining defect and required contour correction, 1 patient experienced a mechanical failure of the non-PSI material (Fig. 3), and 1 patient was reconstructed with a PSI for other reasons. The indications for reconstruction are summarized in Table 1.

All patients underwent operation by a team of senior surgical staff members, consisting of a craniofacial surgeon and plastic surgeon, or craniofacial surgeon and neurosurgeon.

Five patients underwent reconstruction with titanium PSIs, and 15 patients with PEEK PSIs (Fig. 4). The PSIs were designed and manufactured by the engineering department of MUMC (IDEE, Maastricht, the Netherlands), by Xilloc (Geleen, the Netherlands), or KLS Martin (Tuttlingen, Germany). In all cases, the same design protocol was followed. A recent and accurate CT scan of the head of the patient was obtained, not older than 6 months and with a slice thickness $\leq 1 \mathrm{~mm}$, and was delivered to the manufacturing company. After approval of the CT scan quality and segmentation of the CT scan data, an engineer designed the first draft of the PSI. In close cooperation between the engineer and the ordering surgeon, all the subsequent design steps were checked off by the ordering surgeon. This included basic requirements such as outline/curvature/fixation points and PSI material, but also the incorporation of design aspects that could account for the presence of remaining cranioplasty material from earlier reconstructive attempts. At least one instance was noted of direct contact (face-to-face or videoconference) to discuss the details of the case. As a requirement, the ordering surgeon approved the final design in writing (Lethaus et al., 2011). The implants were subsequently manufactured using either subtractive or additive manufacturing techniques.

Records of the duration of the surgical procedure of PSI placement in patients who had previously placed cranioplasty material or remnants of it in situ were available in 7 of 7 cases (group I, $\mathrm{n}=7$ ). The mean duration was $104 \pm 27 \mathrm{~min}$. The duration of the surgical procedure of PSI placement in patients with no remaining cranioplasty material in situ was available in 11 of 13 cases (group II, $\mathrm{n}=11$ ), and was a mean of $86 \pm 36 \mathrm{~min}$. There was no statistically significant difference between the duration of the surgical procedure in group I and group II ( $\mathrm{p}=0.27)$ (Table 2$)$.

Postoperative complications occurred in 2 of 20 cases (10\%). Both complications occurred in group II and both in patients reconstructed with PEEK implants. One patient developed a subcutaneous hematoma that resolved using repeated aspiration. One patient developed a wound infection of the skin and subsequent wound dehiscence that required removal of the PSI (Table 2).

Costs of obtaining PSIs from the manufacturer were available for 6 of 7 cases in group I and 10 of 13 cases in group II. Costs were not significantly different between group I and group II (group I: mean EUR $7536 \pm 2759$, group II: mean EUR $8351 \pm 2087, p=0.51$ ) (Table 2).

\section{Discussion}

In the last decade, experience with PSIs for cranioplasty of skull bone defects has increased tremendously. This is also reflected by an increasing number of publications. At MUMC. all patients with large skull bone defects of more than $100 \mathrm{~cm}^{2}$ have been consistently treated with PSIs since 2004. This retrospective analysis 
Table 2

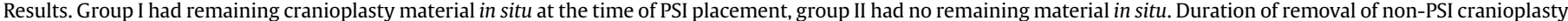

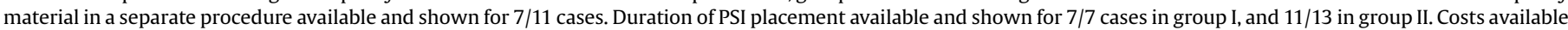

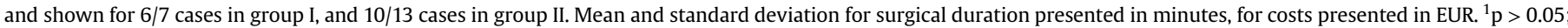
${ }^{2} \mathrm{p}=0.51$.

\begin{tabular}{|c|c|c|c|c|}
\hline \multirow[t]{2}{*}{ Results, $\mathrm{n}=20$} & \multicolumn{2}{|c|}{ Group I $(\mathrm{n}=7)$} & \multicolumn{2}{|c|}{ Group II $(n=13)$} \\
\hline & $\mathrm{n}(\%)$ & Mean (SD) & $\mathrm{n}(\%)$ & Mean (SD) \\
\hline Duration of removal non-PSI cranioplasty & & & & $67( \pm 43)$ \\
\hline Duration of PSI placement ${ }^{1}$ & & $104( \pm 27)$ & & $86( \pm 36)$ \\
\hline Complications & & & $2(10)$ & \\
\hline Costs $^{2}$ & & $7536( \pm 2759)$ & & $8351( \pm 2087)$ \\
\hline
\end{tabular}
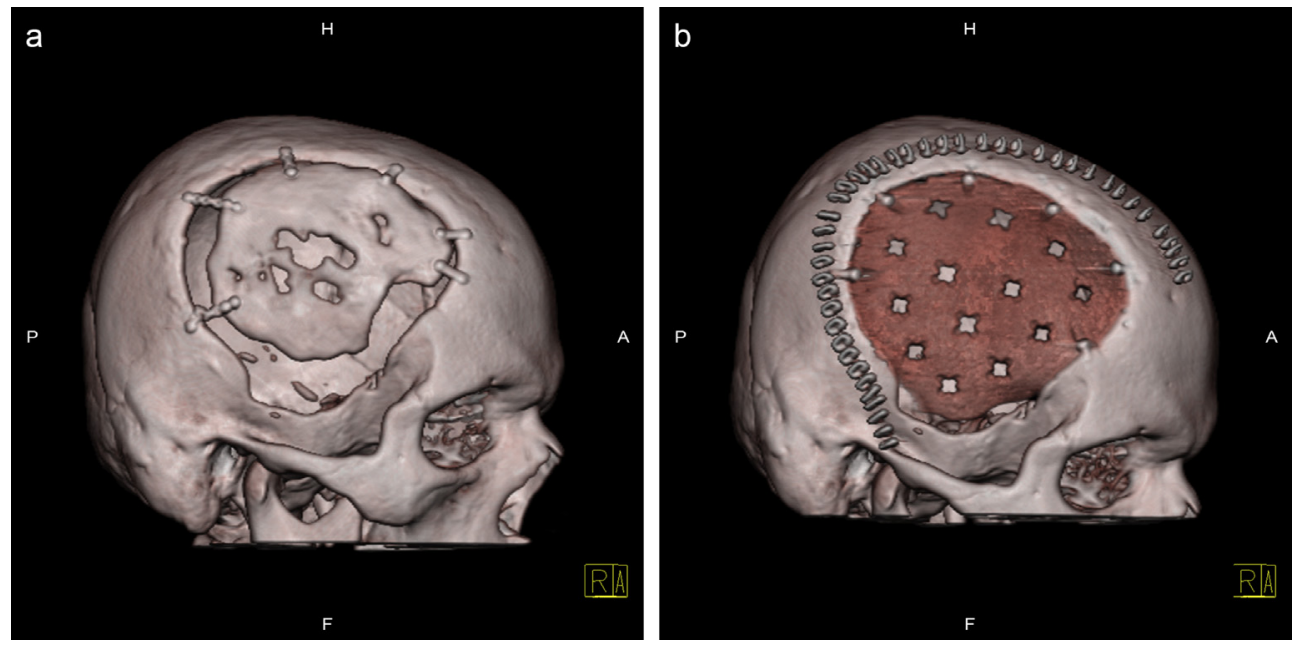

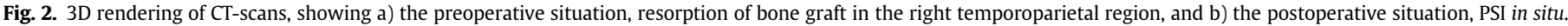
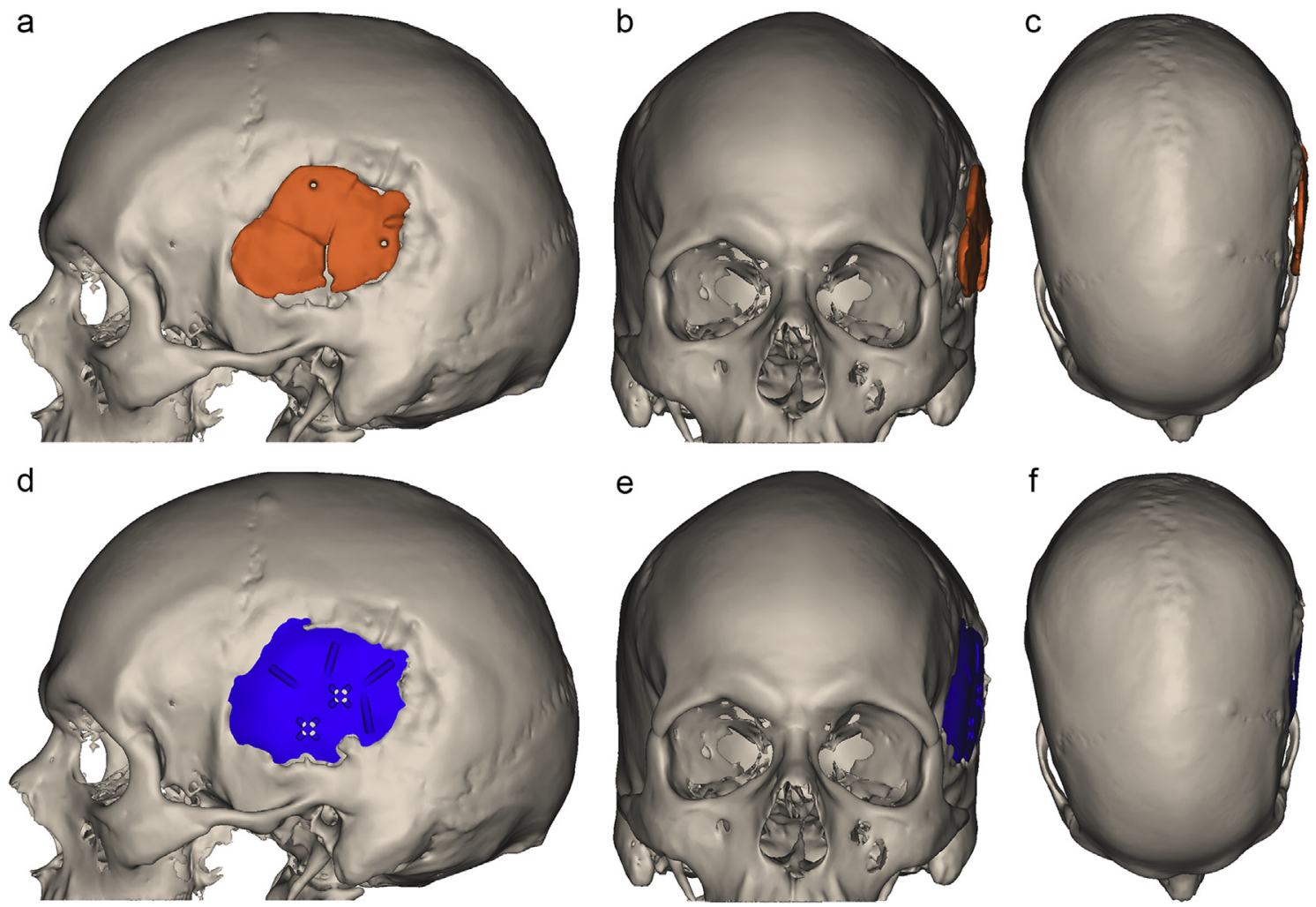

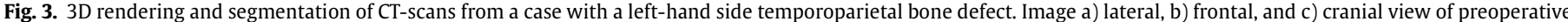

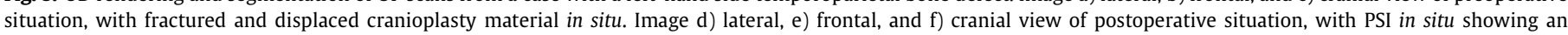
anatomical fit. 

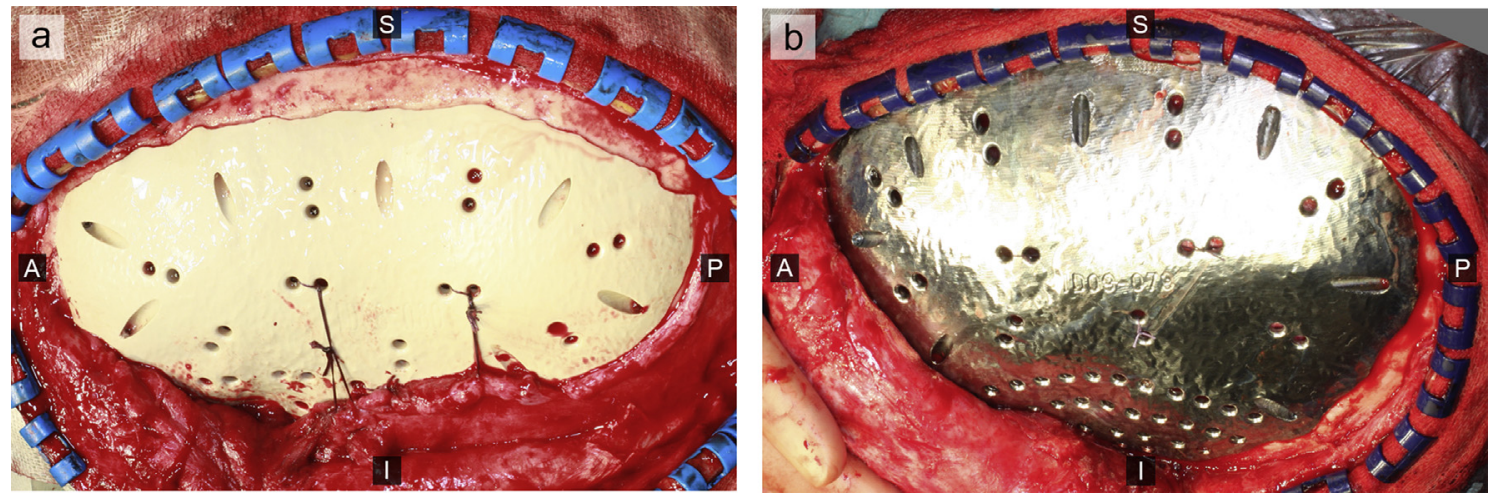

Fig. 4. Clinical images after placement and before skin closure, showing a) a PEEK, and b) a titanium PSI.

focused on those patients in whom repeated surgical interventions to correct the neurocranial defect had not led to success earlier, and in whom residual material, due to bone resorption or failure of previously placed reconstruction material, was often still present at the surgical site.

The irregular surfaces of the wound bed presented no significant challenges for the CAD planning and implant placement. It can be assumed that, because there was no difference between group I and group II concerning operation time, the implant fit was equal in both groups. Also, clinically all implants fitted well without the need for intraoperative corrections to the PSI in both groups, as assessed by the lead surgeon. This might be attributed to accurate preoperative planning, whereby the dimensions of the remaining reconstruction material were assessed, allowing for incorporation of design features that minimized the need for intraoperative manipulation of the remaining reconstruction material. The shift of time to the preoperative planning phase relieves pressure from one of the most costly aspects of surgery: the actual operation time (Shibahashi et al., 2017). The current treatment protocol for PSIs used at MUMC has successfully been used for more than 10 years (Lethaus et al., 2011). Other authors have reported success even though intraoperative manipulation of PEEK implants was necessary (O'Reilly et al., 2015).

Generally, preparation time for the soft tissues and wound bed was greater in patients with residual hard tissues in the defect area. Preparation of the scalp skin layers required great care and experience, because previous multiple operations and infections had severely impaired the structure and quality of the soft tissue coverage. The risk of inducing wound healing disturbances by re-entering the operation site was increased. Pre-existing incisions/scars were always used for preparation. However, due to the multiple interventions, the tissues were scarred and no longer optimally perfused. Furthermore, care was taken to avoid the formation of cerebral fistulas and cerebrospinal fluid leakages. This is the main reason why residual hard tissues in the defect area were often not removed.

The number of postoperative complications after PSI placement in this study was $10 \%$, which is considerably low and corresponds to what is found in the literature. Both complications occurred in patients treated with PEEK PSIs, which is likely attributable to the higher absolute number of patients treated with PEEK PSIs in our patient group. Postoperative hemorrhage occurred in 1 patient, and was treated by repeated aspiration, after which the wound healed primarily. Wound infection and subsequent dehiscence of the skin in the other patient, however, did require an extra surgical procedure to remove the PSI. This case was different from all the others, because the operation time was longer due to an additional neurosurgical intervention in combination with PSI placement. Most importantly, the incision line had to be placed across the defect area. As the wound closure had to be placed on the PEEK implant and not on the patient's bone, it is not surprising that the wound breakdown happened exactly over the PEEK implant. For future cases, it should be stressed that the scalp incision should never be placed across the defect and that the implant should always be securely covered by intact skin. The prolonged operation time could have also played a role in this event (Shibahashi et al., 2017). In accordance with the patient, no further reconstructive attempt will be made, since several infections had occurred before the PEEK PSI placement. In PEEK implant case series, complication rates between $0 \%$ and $35 \%$ have been reported, next to surgical removal rates ranging from $0 \%$ to 18.2\% (Ng and Nawaz, 2014; Alonso-Rodriguez et al., 2015; Gerbino et al., 2015; O'Reilly et al., 2015). No complications were seen in patients receiving a titanium cranioplasty; however, it should be noted that only a limited number of patients were treated with titanium PSIs. In the literature, complication rates of titanium PSIs are reported varying from $4.1 \%$ to $29 \%$, with surgical removal rates ranging from 0\% to 15.9\% (Kung et al., 2012; Wiggins et al., 2013; Williams et al., 2016).

Infection was the main reason for failure in previous reconstructive attempts. Treating the infected non-PSI cases involved at least one additional hospitalization and surgical procedure for removal of the infected primary cranioplasty material, which poses a burden not only to the patients and their social environment emotionally and economically, but also to the medical infrastructure, possibly even more so in an acute setting. Increasing the predictability of the first reconstructive procedure will contribute to decreasing the number of surgeries needed, and will benefit these high-risk patients, as more surgical interventions do not necessarily lead to better results. More data prove that the gold standard practice of replacing the original autologous bone graft may be becoming obsolete and that use of alloplastic materials could be advised as the primary means of repair (Lethaus et al., 2014; Schwarz et al., 2015; Honeybul et al., 2017).

The initial diagnosis for craniectomy in all relevant studies describing cranioplasty is diverse, as has been seen here. In nearly all patients, the gold standard practice of using autologous bone (i.e., replacing the original bone graft) was followed as a first attempt to reconstruct the defect. Only in the cases where the autologous bone graft was absent or unsuitable were other materials used. Not only technical aspects play a role in immediate or delayed reconstruction: the neurological and general condition of the patient may be impaired, and this may increase the complexity of surgery or even lead to inoperability.

The ultimate goal of reconstruction is to improve the neurological function of the patient by restoring the integrity of the skull (Poeck, 1987). A recent study by Zegers et al. showed an overwhelming rate of patient satisfaction after skull bone 
reconstruction. Reconstruction with PEEK or titanium PSIs improved quality of life, decreased pain and headache, while giving aesthetically good results (Zegers et al., 2017). Interestingly, it was often the patient's wish that led to the CAD planning and surgery using PSIs, despite multiple previous operations and despite substantial risks. The study by Zegers et al. is the first ever to retrospectively assess patient satisfaction and quality of life after PSI placement in neurocranial bone defects. According to this study, patient satisfaction should be taken into account in the decision making process of reconstructive options.

Costs have long been considered a major drawback of using PSIs for cranioplasty. Generally authors have balanced the benefits of PEEK PSIs positively against the high costs (Lethaus et al., 2014; Jalbert et al., 2014; Alonso-Rodriguez et al., 2015; O'Reilly et al., 2015). Other authors could not find statistically significant differences in overall costs between autologous bone graft and PEEK cranioplasty or titanium cranioplasty (Gilardino et al., 2015; Honeybul et al., 2017). Our study showed no significant difference in costs for obtaining a PSI from the manufacturer between group I and group II patients, potentially indicating that the preoperative time that an engineer needs to plan and manufacture the implant is not substantially longer in cases in which the remaining reconstruction material is still in situ. Over the course of time, the mean price for obtaining a PSI will likely decrease. This is relevant in everyday practice, where management of increasing health care costs is of top priority. Routine production of PSIs for various indications, a broad range of products and rapid advances in digital design and manufacturing, and market forces, are likely to be the main reasons for a cost reduction of these elaborate implants. In our opinion, however, costs should ultimately not be a limiting factor in treating patients who have undergone multiple unsuccessful reconstructions, as these patients should be treated with the best alternative solution.

The overall costs of treatment play an important role in medical decision making today. The majority of patients in our study received two or more surgeries that were ultimately unsuccessful, although the gold standard treatment in reconstructive bone surgery (i.e., the use of autogenous bone) had been followed. Repeated surgery increased the overall costs and medical risks for these highrisk patients. Subsequently, reconstructing the patient with a PSI at a later stage increased the overall costs and perioperative risks further. Overall costs and perioperative risks can likely be decreased when PSIs are used as the primary reconstructive solution, specifically in class III, IV, V and VI neurocranial defects.

Of course, PEEK is a material for current use. In the future, one would want bioactive implants that are not only accepted by surrounding tissues but are integrated as part of a living organism.

Limitations of the current study are the relatively small number of cases in our cohort, and the retrospective study design, which force us to interpret the presented results with caution. Furthermore, long-term results in PSI placement in neurocranial bone defects are still missing.

\section{Conclusion}

Treatment of skull bone defects in repeated reconstruction requires optimal preoperative planning and intraoperative execution. In this retrospective study in patients with remaining cranioplasty material in situ, we could not find significant differences in the duration of the surgical procedure or costs of cranioplasty, compared to those for patients without remaining material. The protocol followed at MUMC for preoperative planning, manufacturing, and surgery represents the current state-of-the-art treatment. In future studies, we will focus on the biological activity of cranioplasty materials to improve integration in the body.

\section{Conflicts of interest}

The authors declare no conflict of interest.

\section{Acknowledgments}

This study was supported by a research grant under the Brightlands Materials Center Program on Additive Manufacturing: 3D Printing Biomedical Applications.

\section{References}

Alonso-Rodriguez E, Cebrián JL, Nieto MJ, Del Castillo JL, Hernández-Godoy J Burgueño M: Polyetheretherketone custom-made implants for craniofacial defects: report of 14 cases and review of the literature. J Craniomaxillofac Surg 43: 1232-1238, 2015

Brommeland T, Rydning PN, Pripp AH, Helseth E: Cranioplasty complications and risk factors associated with bone flap resorption. Scand J Trauma Resusc Emerg Med 23: 75, 2015

Gerbino G, Zavattero E, Zenga F, Bianchi FA, Garzino-Demo P, Berrone S: Primary and secondary reconstruction of complex craniofacial defects using polyetheretherketone custom-made implants. J Craniomaxillofac Surg 43: 1356-1363, 2015

Gilardino MS, Karunanayake M, Al-Humsi T, Izadpanah A, Al-Ajmi H, Marcoux J, et al: A comparison and cost analysis of cranioplasty techniques: autologous bone versus custom computer-generated implants. J Craniofac Surg 26: 113-117, 2015

Hng D, Bhaskar I, Khan M, Budgeon C, Damodaran O, Knuckey N, et al: Delayed cranioplasty: outcomes using frozen autologous bone flaps. Craniomaxillofac Trauma Reconstr 8: 190-197, 2015

Honeybul S, Morrison DA, Ho KM, Lind CRP, Geelhoed E: A randomized controlled trial comparing autologous cranioplasty with custom-made titanium cranioplasty. J Neurosurg 126: 81-90, 2017

Jalbert F, Boetto S, Nadon F, Lauwers F, Schmidt E, Lopez R: One-step primary reconstruction for complex craniofacial resection with PEEK custom-made implants. J Craniomaxillofac Surg 42: 141-148, 2014

Kimchi G, Stlylianou P, Wohl A, Hadani M, Cohen ZR, Zauberman J, et al: Predicting and reducing cranioplasty infections by clinical, radiographic and operative parameters - a historical cohort study. J Clin Neurosci. https://doi.org/10.1016/ j.jocn.2016.06.007, 2016

Kung W-M, Lin F-H, Hsiao S-H, Chiu W-T, Chyau C-C, Lu S-H, et al: New reconstructive technologies after decompressive craniectomy in traumatic brain injury: the role of three-dimensional titanium mesh. J Neurotrauma 29: 2030-2037, 2012

Lethaus B, Bloebaum M, Koper D, Poort-Ter Laak M, Kessler P: Interval cranioplasty with patient-specific implants and autogenous bone grafts-success and cost analysis. J Craniomaxillofac Surg 42: 1948-1951, 2014

Lethaus B, Laak ter MP, Laeven P, Beerens M, Koper D, Poukens J, et al: A treatment algorithm for patients with large skull bone defects and first results J Craniomaxillofac Surg 39: 435-440, 2011

$\mathrm{Ng}$ ZY, Nawaz I: Computer-designed PEEK implants: a peek into the future of cranioplasty? J Craniofac Surg 25: e55-e58, 2014

O'Reilly EB, Barnett S, Madden C, Welch B, Mickey B, Rozen S: Computed-tomography modeled polyether ether ketone (PEEK) implants in revision cranioplasty. J Plast Reconstr Aesthet Surg 68: 329-338, 2015

Park E-K, Lim J-Y, Yun I-S, Kim J-S, Woo S-H, Kim D-S, et al: Cranioplasty enhanced by three-dimensional printing: custom-made three-dimensional-printed titanium implants for skull defects. J Craniofac Surg 27: 943-949, 2016

Poeck K: Neurologie. Berlin, Heidelberg: Springer Berlin Heidelberg. https://doi.org/ 10.1007/978-3-662-08953-8, 1987

Poukens J, Laeven P, Beerens M, Nijenhuis G, Sloten JV, Stoelinga P, et al: A classification of cranial implants based on the degree of difficulty in computer design and manufacture. Int J Med Robot 4: 46-50, 2008

Schwarz F, Dünisch P, Walter J, Sakr Y, Kalff R, Ewald C: Cranioplasty after decompressive craniectomy: is there a rationale for an initial artificial bonesubstitute implant? A single-center experience after 631 procedures. J Neurosurg: 710-715, http://dxdoiorg/103171/20154JNS159; 2015

Shibahashi K, Hoda H, Takasu Y, Hanakawa K, Ide T, Hamabe Y: Cranioplasty outcomes and analysis of the factors influencing surgical site infection: a retrospective review of more than 10 Years of institutional experience. World Neurosurg 101: 20-25, 2017

Wiggins A, Austerberry R, Morrison D, Ho KM, Honeybul S: Cranioplasty with custom-made titanium plates-14 years experience. Neurosurgery $72: 248-256$, 2013 discussion 256

Williams L, Fan K, Bentley R: Titanium cranioplasty in children and adolescents. J Craniomaxillofac Surg 44: 789-794, 2016

Zanotti B, Zingaretti N, Verlicchi A, Robiony M, Alfieri A, Parodi PC: Cranioplasty: review of materials. J Craniofac Surg 27: 2061-2072, 2016

Zegers T, Laak-Poort ter M, Koper D, Lethaus B, Kessler P: The therapeutic effect of patient-specific implants in cranioplasty. J Craniomaxillofac Surg 45: 82-86, 2017 